\title{
Stage II Appendix Carcinoma AJCC v8
}

National Cancer Institute

\section{Source}

National Cancer Institute. Stage /I Appendix Carcinoma A/CC v8. NCI Thesaurus. Code C134121.

Stage II includes: IIA: T3, N0, M0; IIB: T4a, N0, M0; IIC: T4b, N0, M0. T3: Tumor invades through the muscularis propria into the subserosa or the mesoappendix. T4a: Tumor invades through the visceral peritoneum, including the acellular mucin or mucinous epithelium involving the serosa of the appendix or serosa of the mesoappendix. T4b: Tumor directly invades or adheres to adjacent organs or structures. N0: No regional lymph node metastasis. M0: No distant metastasis. (AJCC 8th ed.) 